\title{
Twins and Friendship
}

\author{
Karen Thorpe \\ School of Early Childhood, Queensland University of Technology, Australia
}

\begin{abstract}
growing body of literature asserts the importance of friendships for a child's emotional wellbeing, behavioural adjustment and developmental attainment. However, few studies have examined friendships in the twin situation. This paper examines the literature on friendships among children who are twins and asks two questions: (1) What are the implications of the twin situation for friendship formation? (2) How can the twin situation inform theoretical knowledge concerning friendship formation in the general population? The discussion examines the implications of the twin situation for the size and nature of twin children's friendship pool and questions whether children who are twins are more likely to be adaptive or maladaptive in their social behaviour. The paper argues for the need to study the process and mechanisms in friendship formation among twin children because the findings might inform not only studies of friendship but also behavioural genetic research.
\end{abstract}

Friends play an important role in children's development (Bukowski et al., 1996; Vaughn et al., 2000; Vaughn et al., 2001). Friends are a cognitive and social resource for children (Hartup, 2000). They provide children with a context for social skill learning, and are models for later relationship development (Bukowski et al., 1996). Children who have supportive relationships have been found to adjust more readily to life transitions while difficulties with friendship have been associated with both concurrent and long-term adjustment problems (Berndt, 1996; Bukowski et al., 1996; Ladd, 1990; Ladd et al., 1996). The weight of research evidence asserts that friends have a normative developmental significance; however, there is individual variation in how friends affect development with the identity of the friend and the quality of the relationship differentiating outcome (Hartup, 2000). Most importantly, the quality of early relationships has been found to interact with environment and peer relationships to affect behavioural outcomes (Hartup \& Van Lieshout, 1995).

This paper argues that the study of twin children and their friendships is important in two distinct ways. First, the study of twin children's friendships is important in its own right. There is a considerable literature devoted to investigating the risk of psychopathology among twins and yet there is little concerning their peer relationships and friendships which might contribute to behaviour adjustment. Second, the study of twin children's friendships might inform the theoretical understanding of friendship formation in the population as a whole.

The paper addresses two key questions. (1) What are the implications of the twin situation for friendship formation? (2) How can the twin situation inform theoretical knowledge concerning friendship formation in the general population?

\section{What Are the Implications of the Twin Situation for Friendship Formation?}

Twinship presents a unique set of circumstances within which to negotiate social relationships. In early childhood twin children rarely encounter social settings in absence of their sibling (Rutter et al., 2003, Thorpe et al., in press). Available research suggests that, even in the early school years, twins share much of their social world (Koch, 1966; Preedy, 2001). As a consequence a twin child's negotiation of friendships with peers is different from that of a singleton child in two distinct ways. First, a child in a twin pair has a lifelong and constant relationship with an individual of the same age. In contrast to a singleton, who will more often have time alone and with a dedicated adult, the social world of twins is one in which another child is invariably present and which necessitates greater levels of interaction, most notably, providing experience of negotiation, sharing and turn-taking. Further, a twin's established relationship with a co-twin will affect the dynamics of social interactions with peers. It may provide a secure base on which other friendships are built or, at the other extreme, be highly dependent and impede establishment of other relationships. Second, a twin child's friendships are established in the presence of his or her co-twin. This may mean that twins are seen as competitors for friendships or that they are viewed as a single unit and, therefore, somewhat unusual or unique.

Two key research questions emerge from the observations of the unique social setting presented by twinship.

1. Is the size and nature of friendship pool different for twins compared with singletons?

2. Does the twin situation, and specifically its influence on friendship patterns, mediate adaptive or maladaptive behaviours?

\section{Is the Size and Nature of Friendship Pool Different for Twins Compared with Singletons?}

There are only a few systematic studies of friendship patterns among twins. The earliest of these, conducted by Koch (1966), examined the friendships of twins aged

Address for correspondence: Karen Thorpe, School of Early Childhood, Queensland University of Technology, Victoria Park Rd, Kelvin Grove QLD 4059, Australia. Email: k.thorpe@qut.edu.au 
59-86 months and compared them with a sample of matched singletons of the same age. This study indicated that the number of playmates identified by twins did not differ from that identified by their singletons counterparts. Ratings of closeness of the twin pair were not found to be associated with number of playmates. Both this study and two subsequent studies (Preedy, 2001; Rose, 2002) indicate that it is not the size of the friendship pool which distinguishes twin children's friendship patterns but rather that a proportion of their friends are shared (Koch, 1966; Preedy, 2001; Rose, 2002). Preedy (2001) in a survey of more than 11,000 twins (4- to 5-year-olds) entering their first school year in Britain found that only $8 \%$ of twins had their own circle of friends, the majority had shared friends while $20 \%$ stayed together and had few other friends. Koch similarly reports twins to have shared friendships. Further, she indicates that $\mathrm{MZ}$ twins play more together and have more shared friendships than DZ twins. Rose (2002) presents evidence that this pattern continues into adolescence. In his study of same-sex adolescent twins he reports that MZ pairs are more likely than $\mathrm{DZ}$ pairs to nominate each other or common classmates as best friends.

The available data are cross-sectional providing snapshots of children at a single point in time and for two developmental periods: Preedy (2001) and Koch (1966) focus on early childhood and Rose (2002) adolescence. Nevertheless, together they present a consistent picture. None report differences in the number of friends of twins compared with singletons and all suggest that shared friendship is a part of twin situation which occurs more frequently among $\mathrm{MZ}$ as compared with $\mathrm{DZ}$ twins. The existence of shared friendships among twin children suggests a difference in dynamics compared with singletons and raises the question of the effect of the twin situation on social behaviour and development.

\section{Does the Twin Situation, and Specifically its Influence on Friendship Patterns, Mediate Adaptive or Maladaptive Behaviours?}

The significance of the existing findings concerning twin children's friendships is not known. The development of friendship among twins has not been systematically documented and the long term impact of their unique social situation is not established. A substantial body of research has focused on psychopathology and the hypothesis that the twin situation raises risk (Gau et al., 1992; Gjone \& Novik, 1995; Levy et al., 1996; Lytton et al., 1987; Simonoff, 1992). Two associates of the twin situation are identified as potential mechanisms which may increase rates of psychopathology among twins:

1. Biological hypothesis: that greater adversity in the pre and perinatal environment might predispose to subtle neurological damage which accounts for psychopathology among the general twin population (which excludes twins that have overt neurological damage).

2. Social hypothesis: that disruption to normal patterns of social interaction, observed in singletons, is brought about by the presence of two children of the same age and that this might predispose to psychopathology. These disturbances include having to share adult attention; spending more time in the presence of a same-age child and secondary effects such as raised level of parental stress and depression associated with multiple birth (Thorpe et al., 1991).

The focus of research pertaining to the social hypothesis has centred on interactions within the family, though clearly friendships sit within this hypothesis.

A raised risk of psychopathology among twins is not established. Rutter and Redshaw (1991) concluded from their extensive review of the literature that "overall the risk for socioemotional behavioural disturbance in twins is not much different from that found in singletons" (p. 892). However, in the 12 years since this review studies have continued to pursue the hypothesis that the twin situation raises risk. While some studies have reported no differences between twins and singletons in the rates of psychopathology (Gjone, 1995; Van den Oord, 1995) others suggest raised levels of externalizing behaviour (Gau, 1992; Levy, et al., 1996; Simonoff, 1992). In contrast, a recent study has suggested that the twin situation might promote adaptive social behaviour (Pulkkinen et al., 2003). In this study adolescents (aged 11-12) rated the social behaviour of classmates in a sample of more than 1000 classes in schools across Finland. The classes were those of 1874 twin pairs in the Finnish Twin cohort though the study was not identified as a twin study. Comparison of ratings of twins with gender matched singleton classmates indicated that twins were rated more highly in adaptive behaviours. This effect was particularly evident for opposite sex pairs.

The conflicting results in the current body of studies indicate the need for more specific examination of the association of the twin situation with social behaviour across its continuum. Where specific disorders are a focus the need to unpack mechanisms and pathways is evident. Detailed study of twin children's social relationships will inform this research because they represent a potential underlying mechanism for either raised levels of psychopathology or social skill. One important dimension of this work is the examination of how language delay, which occurs more frequently in twins, and particularly male twins, affects social relationships and social behaviour. Koch (1966) provides data indicating an association between language skills and social interaction during early childhood. However, to date, there are no longitudinal data on friendship formation and social behaviour. There is a need to track the interplay of family interaction, social experience and peer interaction. Key transition points such as entry to childcare and school warrant particular attention. The relationship of co-twins and variation across twin type might be informative. For example, the early study of Koch (1966) indicates that among male twins in an opposite sex pair compatibility with their co-twin was associated with popularity, involvement with children and social confidence. Large scale longitudinal studies of twins and singleton comparisons focusing on friendship and social behaviour are warranted. Alongside large scale studies those which obtain the accounts of friendship and social behaviour from twin children themselves would provide a view of the meaning of social interactions for twin children. 


\section{How Can the Twin Situation Inform Theoretical Knowledge Concerning Friendship Formation in the General Population?}

The twin situation provides a natural experiment for the study of process in friendship formation. Within the twin population the three subgroups: monozygotic (MZ), dizygotic same sex (DZss) and dizygotic opposite sex (DZos) pairs provide contrasts in two key factors in friendship formation: social propinquity and similarity of physical and personal characteristics

Research has identified one key condition of friendship formation in childhood as social propinquity: to become friends children must come into contact with one another. Existing studies provide clear evidence that, particularly in the early years, children who are twins share a great deal of their social environment (Koch, 1966; Preedy, 2001; Rutter et al., 2003; Thorpe et al., in press). However, two very different variations in social environment might inform our understanding of the interplay of social environment and the size and nature of friendship pool. First, studies of variations within the twin population will provide data on both the processes affecting access to a social pool and their association with size of friendship pool. One key variant in this respect is the difference between same sex and opposite sex pairs. Second, the effect of life stage and key transition points is informative. Events which give access to a different social pool, such as entry to day care or school, may change the size and nature of the friendship pool. Of particular interest is the effect of this exposure within pairs and across different twin types. A key question is whether children who are twins share friends because of limitations on their social pool or because they are similar in type; that is because they actively select and are selected by the same individuals as friends.

Similarity has been identified as a key variable underlying friendship formation (Aboud \& Mendelson, 1996). Studies of adolescents, both in same sex friendships and romantic relationships, indicate that similarity of attitudes and behaviours influences interpersonal attraction and distinguish those friendships that founder from those that endure (Cohen, 1977; Kendal, 1978a, 1978b). The study of twins presents the opportunity to examine the role of similarity in friendship formation. Twins are likely to share a social environment and different twin types present variation on both degree of physical and behavioural similarity. This situation enables the study of indices of similarity and overlap of friendships. If similarity is an underlying factor influencing friendship selection, we would expect twin type (MZ, DZss, DZos), an index of similarity, to be associated with shared friendship. Two previous studies indicate that this is the case. Koch (1966) in her study of children in the early years of school reports more shared friendships among MZ twins compared with DZ twins though this study did not measure similarity and therefore could not provide direct evidence of an association with similarity. Rose (2002) reports that MZ pairs are more likely to rate each other or a common classmate as friends. Moreover, friends of $\mathrm{MZ}$ twins were rated as being more similar in type than those of DZ twins. This study provides key evidence of the role of similarity in friendship formation in the sample of adolescents. Studies using similar designs across other developmental stages might establish the degree that individuals seek friends who are like themselves. It may be that this process operates from an early age or that the effect becomes stronger across the developmental course. Again, tracking of twin populations provides an invaluable design in examining process in friendship.

The use of twin designs will not only inform our understanding of process in friendship formation and maintenance but also contribute to our understanding of phenotype-environment interaction with both active (twins select friends) and passive (friends respond to phenotype) genetic effects evident. Consideration of the process in social environment outside the family home informs behavioural genetic research directly in this way and is also pertinent to testing the assumptions of classic twin designs that (1) within pair environmental differences are similar for $\mathrm{MZ}$ and $\mathrm{DZ}$ pairs other than for those that are genetically determined (2) the strength and pattern of genetic and environmental influences as they operate in twins should be similar to those operating in singleton if findings are to be applied to the general population. Available evidence does not challenge these assumptions but there remain many gaps in our knowledge concerning twins and their extrafamilial social relationships.

\section{References}

Aboud, F. E., \& Mendelson, M. J. (1996). Determinants of friendship selection and quality: Developmental perspectives. In W. N. Bukowski, A. F. Newcomb, \& W. W. Hartup (Eds.), The company they keep: Friendship in childhood and adolescence (pp. 87-112). New York: Cambridge University Press.

Berndt, T. J. (1996). Exploring the effects of friendship quality on social development. In W. N. Bukowski, A. F. Newcomb, \& W. W. Hartup (Eds.), The company they keep: Friendship in childhood and adolescence. New York: Cambridge University Press.

Bukowski, W. M., Newcomb, A. F, \& Hartup, W. W. (1996). Friendship: Its significance in childhood and adolescence: Introduction and comment. In W. N. Bukowski, A. F. Newcomb, \& W. W. Hartup (Eds.), The company they keep: Friendship in childhood and adolescence. New York: Cambridge University Press.

Cohen, J. M. (1977). Sources of peer group homogeneity. Sociology of Education, 50, 227-241.

Gau, J. S., Silberg, J. L., Ericson, M. T., \& Hewitt, J. K. (1992). Acta Geneticae et Gemellologiae, 41, 53-63.

Gjone, H., \& Novik, T. S. (1995). Parent ratings or behaviour problems: A twin and general population comparison. Journal of Child Psychology and Psychiatry, 36, 1213-1224.

Hartup, W. W. (2000). The company they keep: Friendships and their developmental significance. In W. Craig (Ed.), Childhood social development. Malden, Massachusetts: Blackwell.

Hartup, W. W. (1983). Peer relations. In P. H. Mussen (Ed.), Handbook of child psychology: Social and personality development (pp. 275-385). New York: John Wiley.

Hartup,W.W., \& Van Lieshout, C. F. M. (1995). Personality development in social context. In J. T. Spence (Ed.), Annual Review of Psychology, 46, 655-687. 
Kandel, D. B. (1978a). Homophily, selection, and socialization in adolescent friendships. American Journal of Sociology, 84, 427-436.

Kandel, D. (1978b). Similarity in real-life adolescent friendship pairs. Journal of Personality and Social Psychology, 36, 306-312.

Koch, H. (1966). Twins and twin relations. Chicago: University of Chicago Press.

Ladd, G. W. (1990). Having friends, keeping friends, making friends, and being liked by peers in the classroom: Predictors of children's early school adjustment? Child Development, 61, 1081-1090.

Ladd, G. W., Kochenderfer, B. J., \& Coleman, C. C. (1996). Friendship quality as a predictor of children's early school adjustment. Child Development, 67, 1103-1118.

Levy, F., Hay, D., McLaughlin, M., Wood, C., \& Waldman, I. (1996). Twin sibling differences in parental reports of ADHD, speech, reading and behaviour problems. Journal of Child Psychology \& Psychiatry \& Allied Disciplines, 37(5), 569-578.

Lytton, H., Watts. D., \& Dunn, B. E. (1987). Twin -singleton differences in verbal ability: Where do they stem from? Intelligence, 11, 359-369.

Parker, J. G. A. (1987). Peer relations and later personal adjustment: Are low-accepted children at risk? Psychological Bulletin, 102, 357-382.

Preedy, P. ( 2001). Are multiple birth children different from singletons? Meeting the educational needs of multiple birth children upon school entry. Unpublished doctoral dissertation, The University Of Birmingham, Birmingham, UK.

Pulkkinen, L., Vaalamo,I., Hietala, R., Kaprio, J., \& Rose, R. J. (2003). Peer reports of adaptive behaviour in twins and singletons: Is twinship a risk or an advantage? Twin Research, 6(2), $106-118$

Rose, R. J. (2002). How do adolescents select their friends? A behavior-genetic perspective. In L. Pulkkinen, \& A. Caspi
(Eds.), Paths to successful development: Personality in the life course (pp. 106-125). New York: Cambridge University Press.

Rutter, M., \& Redshaw, J. (1991). Annotation: Growing up as a twin: Twin-singleton differences in psychological development. Journal of Child Psychology and Psychiatry, 32, 885-895.

Rutter, M., Thorpe, K., Greenwood, R., Northstone, K., \& Golding, J. (2003). Twins as a natural experiment to study the causes of mild language delay I: Design; twin-singleton differences in language and obstetric risks. Journal of Child Psychology and Psychiatry, 44(3), 326-341.

Simonoff, E. (1992). A comparison of twins and singletons with child psychiatric disorders: An item sheet study. Journal of Child Psychology and Psychiatry, 33, 1319-1332.

Thorpe, K. J., Golding, J., MacGillivray, I., \& Greenwood, R. (1991). Comparison of the prevalence of depression in mothers of twins and mothers of singletons. British Medical Journal, 302, 875-878.

Thorpe, K., Rutter, M., \& Greenwood, R. (2003). Twins as a natural experiment to study the causes of mild language delay II: Family interaction risk factors. Journal of Child Psychology and Psychiatry, 44(3), 342-355.

Van den Oord, E. J., Koot, H. M., Boomsma, D. I., Verhulst, F. C., \& Orlebeke, J. F. (1995). A twin-singleton comparison of problem behaviour in 2-3 year olds. Journal of Child Psychology and Psychiatry, 36, 232-245.

Vaughn, B., Azria, M. R, Krzysik, L., Caya, L. R., Bost, K. K., Newell, W., et al. (2000). Friendship and social competence in a sample of pre-school children attending Head Start. Developmental Psychology, 36, 326-328.

Vaughn, B., Colvin, T. N., Azria, M. R, Caya, L., \& Krzysik, L. (2001). Dyadiac analyses of friendship in a sample of preschool-age children attending Head Start: Correspondence among measures and implications for social competence. Child Development, 72(3), 862-878. 